\title{
Influence of Shoulder and Chamfer Margin Design on the Stress Distribution Pattern in Different All Ceramic Restorations by Three-Dimensional Finite Element Analysis
}

Imtiyaz Ahmed Magray', Talib Amin Naqash ${ }^{2 *}$, Shafait Ullah Khateeb ${ }^{3}$, Mohammad Yunis Saleem Bhat ${ }^{4}$ and Muhammad Waqar Hussain ${ }^{5}$

${ }^{1}$ Department of Prosthetic Dentistry, India

${ }^{2}$ Department of Prosthetic Dentistry, KSA

${ }^{3}$ Department of Restorative Dental Science, KSA

${ }^{4}$ Department of Periodontics and Community Dental Sciences, KSA

${ }^{5}$ Department of Prosthetic Dentistry, Pakistan

*Corresponding author: Talib Amin Naqash, Assistant Professor, Department of Prosthetic Dentistry, College of Dentistry, King Khalid University, Abha, KSA.
Received Date: October 27, 2018

Published Date: November 15, 2018

\section{Abstract \\ Purpose: The purpose of this study was to evaluate the influence of shoulder and chamfer margin design on stress distribution pattern in different all ceramic restorations.}

Materials and methodology: Six three-dimensional finite element models representing mandibular second premolar tooth were constructed, using a Finite Element Analysis Software (ANSYS version 14; ANSYS Inc., Canonsburg, PA, USA). Three models each with shoulder and chamfer finish line were created after tooth preparation by reverse engineering, using Pro E software. Each model with shoulder finish line margin had Bruxzir (Glidewell labs), Lava (3M ESPEE) and IPS e.max Press (Ivoclar Vivadent) all ceramic restorations fabricated over them. Same was done with the models having chamfer finish margin. A distributed load of 600 $\mathrm{N}$ was applied on the restorations to analyze the stress distribution pattern in different all ceramic restorations having different marginal geometry. The stress distribution in different groups was compared using one-way ANOVA and Tukey's honest significance test.

Results: Von Mises stresses in the margin region were seen to be lowest in Lava (3M ESPEE) all ceramic restoration with shoulder finish margin when subjected to masticatory bite force. The areas of maximum stress concentration were found in the cervical portion of the all ceramic restorations when subjected to loading forces.

Conclusion: The type of material used, and the type of margin configuration affects the stress distribution pattern within posterior all ceramic restorations.

Keywords: Chamfer; Finite element analysis (FEA); Shoulder

\section{Introduction}

Although metal ceramic restorations have been used for more than three decades with success, demand for superior esthetics and apprehensions regarding biocompatibility of the metal has led to introduction of all-ceramic restorations [1,2]. However, improvements in the esthetics of dental restorations cannot compromise their strength to withstand high masticatory forces [3].

Successful application of all-ceramic materials on the posterior teeth depends on the practitioner's ability to select appropriate all ceramic system with desirable mechanical properties [4]. One of the most important desired mechanical properties of dental 
ceramic restorative material to be used as a posterior restoration is its fracture toughness; dental restorations are routinely subjected to high masticatory load (1031 N for the partially dentate and 1243 $\mathrm{N}$ in patients with a full dentition) [5].

The main limitation for the use of all ceramic restorations in the posterior teeth is their brittleness; ceramics are relatively weak in tension and strong in compression. Tensile forces encourage crack formation and propagation. Crack initiation and propagation depends on the all ceramic system used (micro structure), design of the restoration, thickness of the restoration, margin configuration, size and distribution of surface flaws and magnitude of occlusal load [6-9].

There are few studies in the literature regarding the effect of stress distribution when different tooth preparation designs are applied to different prosthetic restorations. The objective of the study was to evaluate and compare the influence of shoulder and chamfer finish margin design on the stress distribution pattern in dentinal portion of mandibular second premolar using different all ceramic restoration systems (Bruxzir, Lava, IPS e.max Press) by finite element analysis (FEA).

\section{Materials and Methodology}

To evaluate the influence of margin design on the stress distribution of posterior all ceramic restorations; a threedimensional (3D) finite element analysis (FEA) study was conducted [10]. Intact mandibular 2nd Premolar tooth (Frasaco, Germany) was scanned using STEIN BICHLER COMET LED (2M) blue light 3-D scanner (Germany). The scanned model was converted into a surface model using Nx-I-deas 6.1(Unigraphics, Siemen's) software (Figures 1a \& 1b). Tooth preparation was done by reverse engineering process as per the guidelines given by Rosenstiel et al. (Occlusal and proximal clearance of $1.5 \mathrm{~mm}$ except at the functional cusp where the clearance was $2.0 \mathrm{~mm}$ ) [11]. Six models were fabricated; three models with shoulder finish margin and three models with chamfer finish margin (Figures 2a \& 2b). Restorations were fabricated on the prepared teeth by reverse engineering procedure using Pro-E software. Each model with shoulder finish line margin had Bruxzir (Glidewell labs), Lava (3M ESPEE) and IPS e.max Press (Ivoclar Vivadent) restorations fabricated over them (Figures 3a). Same was done with the models having chamfer finish margins (Figures 3b).

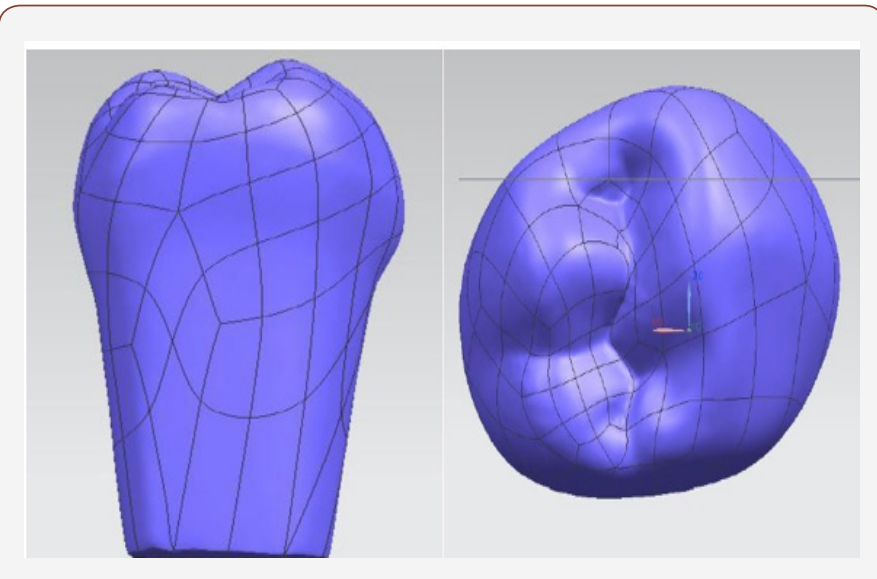

Figure 1: Surface model of the scanned tooth, proximal view (a) occlusal view (b).

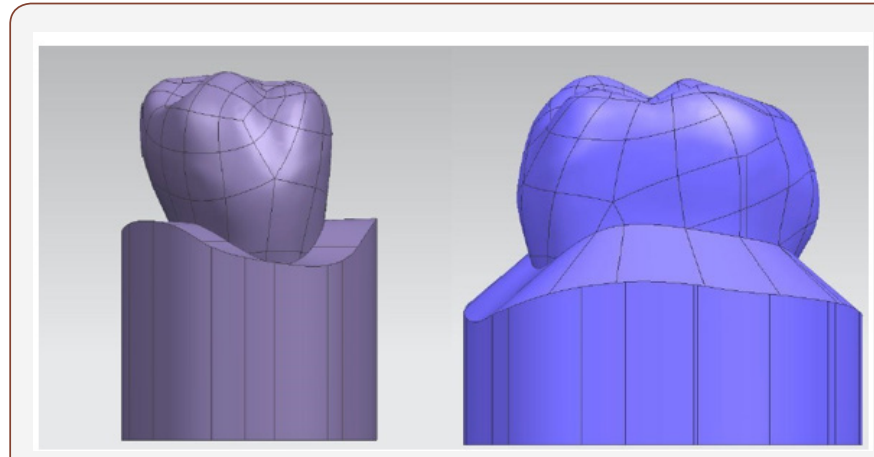

Figure 2: Proximal view of the prepared tooth with shoulder margin (a) and chamfer margin (b).

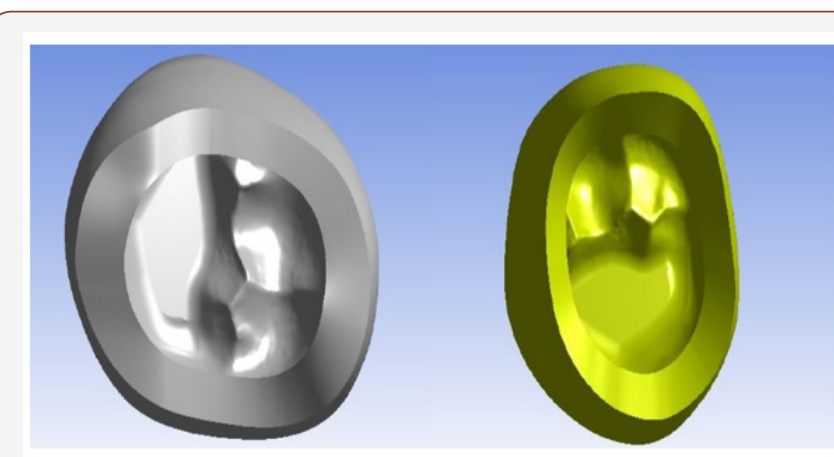

Figure 3: Restoration fabricated on the prepared tooth with shoulder margin (a) and chamfer margin (b).

The three-dimensional finite element models corresponding to the geometric model were generated using FEA software (ANSYS version 14; ANSYS Inc., Canonsburg, PA, USA). Care was taken during meshing to concentrate elements in the region of highest stress distribution pattern (Figures $4 \mathrm{a} \& 4 \mathrm{~b}$ ). Therefore, default element size with SOLID 187 elements was selected. The element was defined as 10 nodes having three degrees of freedom at each node: translations in the nodal $\mathrm{x}, \mathrm{y}$ and $\mathrm{z}$ directions (Table 1).

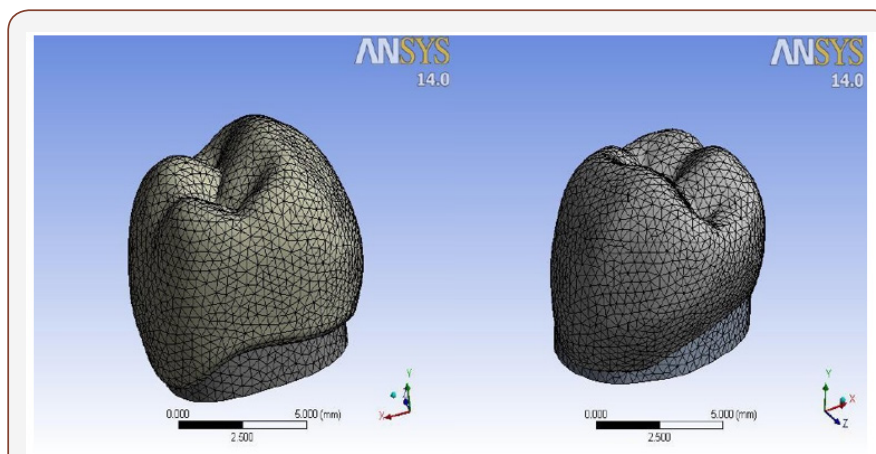

Figure 4: Mesh generated over the ceramic restoration fabricated with shoulder margin (a) and chamfer margin (b).

Table 1: Mesh data showing number of elements and nodes.

\begin{tabular}{|c|c|c|}
\hline & Elements & Nodes \\
\hline Model with shoulder margin finish line & 74755 & 49245 \\
\hline Model with chamfer margin finish line & 80651 & 53377 \\
\hline
\end{tabular}

The models were fixed in the nodes at the surface of the alveolar bone and following assumptions were included in the finite element model: (1) Dentin, pulp chamber and periodontal ligament in the mathematical model were assumed to be linearly 
elastic, homogeneous and isotropic [12].(2) No slip was permitted between components (perfect bonding) (3) It was assumed that enamel is completely removed during tooth preparation. (4) The influence of the periodontal ligament on the stress distribution of the crown is negligible. (5) There are no flaws in any component. All nodes in the $x-y-z$ planes, which correspond to the root portion of the prepared tooth, are assumed to be fixed; no translation or rotation is allowed in any direction.

The corresponding elastic properties such as Young's modulus and Poisson's ratio of dentin, and the three all ceramic restorations were determined from the literature and are presented in Table 2 [13-15].

Table 2: Material Properties assigned to the models.

\begin{tabular}{|c|c|c|}
\hline & $\begin{array}{c}\text { Modulus of } \\
\text { Elasticity (MPa) }\end{array}$ & $\begin{array}{c}\text { Poison's } \\
\text { Ratio }\end{array}$ \\
\hline Dentin & 18600 & 0.31 \\
\hline Bruxzir (Glidewell labs) & 200000 & 0.3 \\
\hline Lava (3M ESPEE) & 216000 & 0.27 \\
\hline IPS e.max press (Ivoclar Vivadent) & 95000 & 0.23 \\
\hline
\end{tabular}

Symmetrical boundary conditions were imposed all over the prepared tooth. On the proximal sides all the three translations were fixed indicated by light blue color triangles.

A distributed load of $600 \mathrm{~N}$ on the buccal cusp tip, lingual cusp tip, lingual and buccal inclines of the occlusal surface, and central developmental groove was applied on each sample. The magnitude and the direction of the loading forces was according to the previous studies conducted by Kaarel Proos et al. [16] and are presented in Table 3.

Table 3: Loading protocol followed in the study.

\begin{tabular}{|c|c|c|}
\hline Force direction (in degrees) & Vertical (90 & $\begin{array}{c}\text { Oblique } \\
(\mathbf{4 5})\end{array}$ \\
\hline Force magnitude (in newton) & $600 \mathrm{~N}$ & $600 \mathrm{~N}$ \\
\hline Model with chamfer margin finish line & 80651 & 53377 \\
\hline
\end{tabular}

The stress distribution in different groups was compared using one-way ANOVA and Tukey's honest significance test, and results were tabulated.

\section{Results}

Results were determined by considering von Mises criteria. Failure occurs when von Mises stress values exceed the yield strength of the ceramic restorations. Therefore, they are important for interpreting the stresses occurring within the ceramic restorations.

The FEA revealed stresses at every node in each model. These results were displayed as stress contours overlaid on the original model. The calculated numeric data of stress in the models were transformed into color graphics. The mean von Mises stress values within different posterior ceramic restorations using different margin design configuration were tabulated, as indicated in (Table $4 \& 5)$.

Table 4: Comparison of stress distribution of different posterior all ceramic restorations with respect to margin design using different materials.

\begin{tabular}{|c|c|c|c|c|c|c|}
\hline Material & Margin & $\mathbf{N}$ & Mean & S.D. & 'p' Value* & Significance $* *$ \\
\hline \multirow{2}{*}{ Bruxzir } & Chamfer Finish & 3 & 644.89 & 252.12 & $<0.001$ & Significant \\
\hline & Shoulder Finish & 3 & 473.9 & 103.92 & & \\
\hline \multirow{2}{*}{ LAVA } & Chamfer Finish & 3 & 497.8 & 211 & $<0.001$ & Significant \\
\hline & Shoulder Finish & 3 & 323.91 & 115.59 & & \\
\hline \multirow{2}{*}{ IPS emax press } & Chamfer Finish & 3 & 635.26 & 239.83 & $<0.001$ & Significant \\
\hline & Shoulder Finish & 3 & 502.4 & 174.66 & & \\
\hline
\end{tabular}

*One-way ANOVA ** Tukey HSD

Table 5: Comparison of stress distribution of different posterior all ceramic restorations with respect to materials using different marginal designs.

\begin{tabular}{|c|c|c|c|c|c|}
\hline Finish Line & Material & N & Mean & S.D. & Significance** Value* \\
\hline Chamfer & Bruxzir & 3 & 644.89 & 252.12 \\
\hline & LAVA & 3 & 497.8 & 211 & - \\
\hline & IPS e.max Press & 3 & 635.26 & 103.92 \\
\hline Shoulder & Bruxzir & 3 & 473.9 & - \\
\hline & LAVA & 3 & 323.91 & 115.59 & - \\
\hline
\end{tabular}

On comparison of the stress distribution of different margin designs fabricated with Bruxzir restoration (Table 4), the results showed that the von Mises equivalent stress of shoulder finish margin (473.90 MPa, SD 103.92) (Figure 5a) was lesser than the chamfer margin (644.89 Mpa, SD 252.12) (Figure 5b). On performing One-way ANOVA test, the $\mathrm{p}$ value was found to be statistically significant $(\mathrm{p}<0.001)$. 


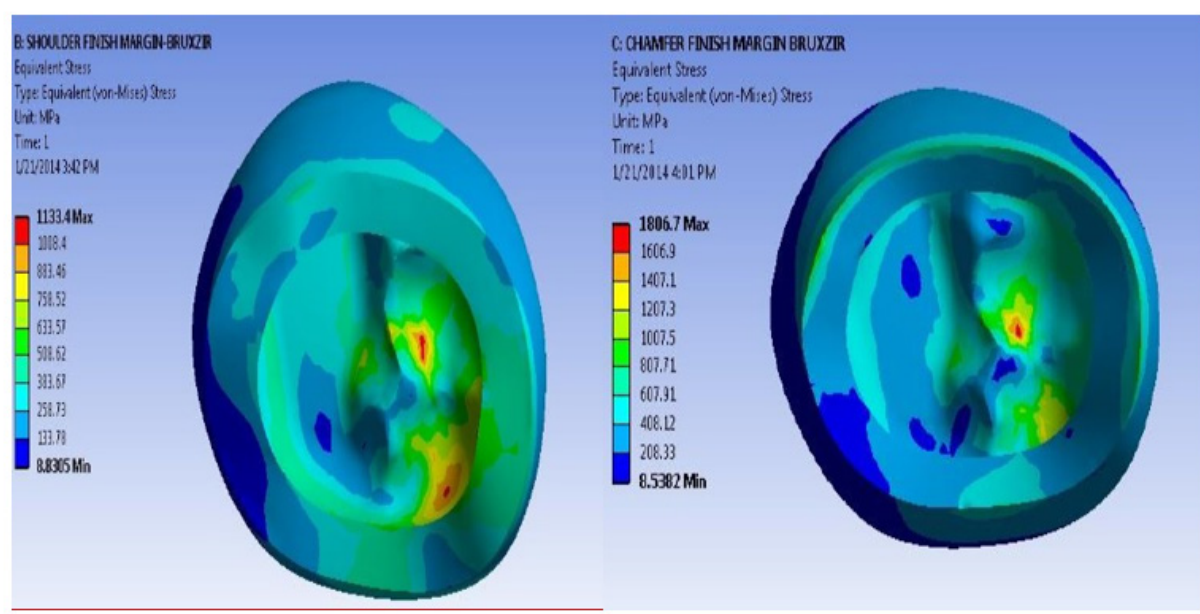

Figure 5: Stress distribution on the Bruxzir restoration along the shoulder margin (a) and Chamfer margin (b).

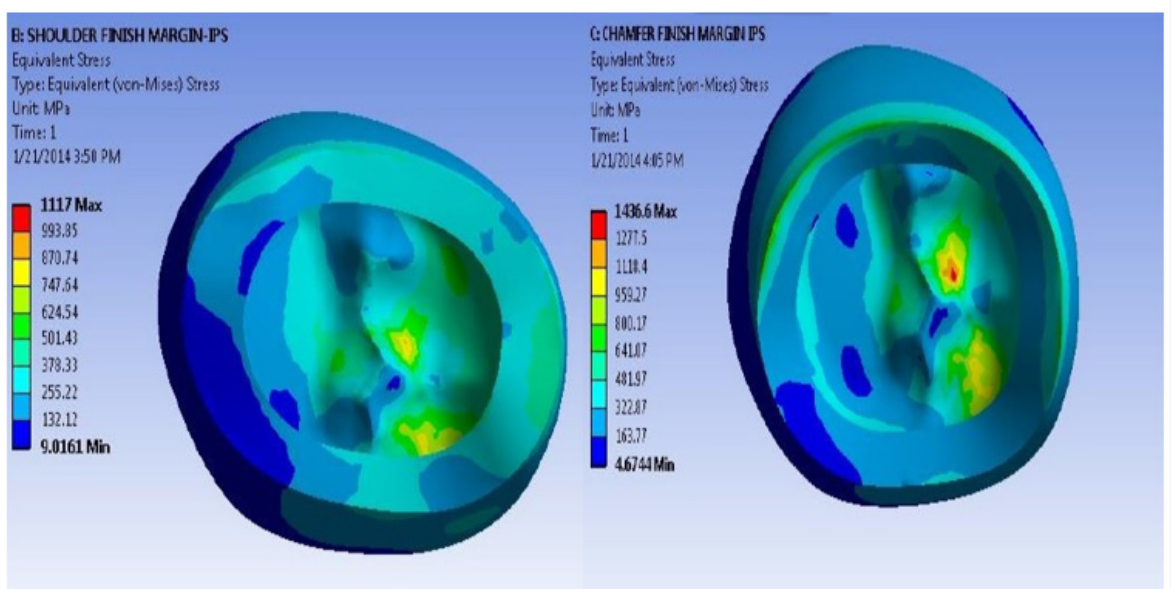

Figure 6: Stress distribution on the IPS e.max Press restoration along the shoulder margin (a) and Chamfer margin (b).

Comparison of stress distribution of different margin designs fabricated with IPS e.max Press restoration is depicted in Table 4. The results showed that the von Mises equivalent stress of shoulder finish margin (502.40 MPa, SD 174.66) (Figure 6a) was lesser than chamfer margin (635.83 MPa, SD 239.83) (Figure 6b) was higher than. On performing One-way ANOVA test, the $\mathrm{p}$ value was found to be statistically significant $(\mathrm{p}<0.001)$.

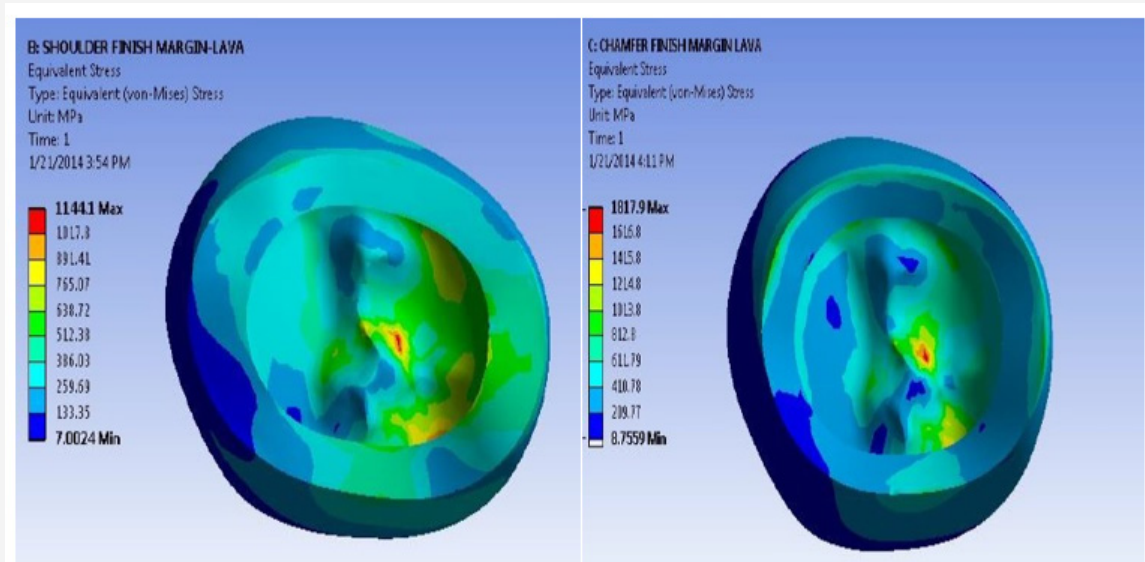

Figure 7: Stress distribution on the Lava restoration along the shoulder margin (a) and Chamfer margin (b).

Table 4 shows the comparison of stress distribution of different margin designs fabricated with Lava restoration. The results show that the von Mises equivalent stress of shoulder finish margin (323.91 MPa, SD 115.59) (Figure 7a) was lesser than chamfer margin (497.80MPa SD 211.00) (Figure 7b). On performing Oneway ANOVA test, the $\mathrm{p}$ value was found to be statistically significant $(\mathrm{p}<0.001)$. 


\section{Discussion}

The results from the study support the rejection of the null hypothesis that the type of all ceramic materials used and the marginal geometry to fabricate posterior all ceramic restorations would not affect the stress distribution pattern within the restoration of a mandibular second premolar tooth. It was observed that the materials and the marginal finish line have an effect on the stress distribution pattern within the restoration when subjected to different loading conditions.

Von Mises stresses in the margin region were seen to be highest in the chamfer margin with Bruxzir restoration while the least were recorded for the shoulder finish margin preparation with Lava restoration. The stress distribution area was larger for shoulder margin preparation, followed by chamfer margin. The stress values within the restoration were highest for the Bruxzir, followed by the IPS e.max Press and the least for the Lava posterior all ceramic restorations for each of the two marginal finish line design.

In shoulder finish line preparation designs, the flexibility of the ceramic structure decreased as a result of the increase in the thickness of the coping material. So, it is concluded that less shear stress developed in the porcelain structure. Therefore, one may accept that a restoration with shoulder finish margin preparation will be structurally strong.

When the shoulder margin preparation design was compared, it was observed that the increase in the modulus of elasticity of the coping material resulted in the decrease in the stress values in the restoration, regardless of the type of marginal preparation used. More stress was observed in the IPS e.max Press ceramic restoration than the Lava and Bruxzir restoration. The shoulder margin preparation design had more homogenous stress distribution than the chamfer margin preparation design in the ceramic restoration with zirconia coping (Lava and Bruxzir) than the lithium disilicate coping (IPS e.max Press). Therefore, preparation design should have shoulder finish margin with the zirconia restoration preferably Lava.

In addition, the present study revealed areas of maximum stress concentration in the cervical portion of the restoration when subjected to loading forces (Figures 5-7). This finding was in agreement with a past report proposed by Hojjatie and Anusavice. [17] They attributed this phenomenon to the bending and deformation of the tooth toward the lingual side, upon horizontal loading.

There are few studies in the literature about the effect of stress distribution when different prosthetic restorations are applied to different tooth preparation design [18-21]. The results of this study complement those of the previous studies since it seeks to examine effects that differ from those mentioned in the above studies.

The study had the following limitations. The Finite element analysis is a software-based study, so the conditions may not match the in vivo conditions accurately. The models used in this study had the ideal preparation design, while the teeth prepared in humans have some inadequacy because of anatomy of the tooth and oral environment conditions. These variables, however, may not be replicated in a badly damaged posterior tooth in a clinical situation.
All the conditions were considered to be ideal; however, the amount and direction of loading in different individuals are not similar. In addition, several assumptions were made during designing of the models.

The restoration is subjected to occlusal loads which vary dramatically in magnitude, frequency, and duration [22]. This can result in considerable stress concentration within the restoration, which can further result in crack formation and propagation causing fracture and structural failure [23]. Thus, the stress distribution within a system can be used as an indicator of its biomechanical behavior [24]. Since Lava all ceramic restoration with shoulder marginal design exhibited maximum amount of stress distribution on masticatory bite force loading, it can be considered as biomechanically favorable for fabrication of a full coverage crown on posterior tooth, in terms of wider stress distribution.

\section{Conclusion}

Within the limitations of the present study, the following conclusions were drawn:

a. Von Mises stresses in the margin region were seen to be highest in the chamfer margin with Bruxzir restoration while the least were recorded for the shoulder finish margin with Lava restoration.

b. Lava all ceramic restoration with shoulder finish margin allowed the maximum amount of stress distribution to the underlying dentin when subjected to loading forces.

c. Therefore, preparation design should have shoulder margin design on the zirconia restoration preferably Lava.

\section{Acknowledgement}

None.

\section{Conflict of Interest}

None.

\section{References}

1. Kelly JR, Nishimura I, Campbell SD (1996) Ceramics in dentistry historical roots and current perspectives. J Prosthet Dent 75(1): 18-32.

2. Heffernan MJ, Aquilino SA, Diaz-Arnold AM, Haselton DR, Stanford CM, et al. (2002) Relative translucency of six all-ceramic systems. Part II: core and veneer materials. J Prosthet Dent 88(1): 10-15.

3. Fischer H, Marx R (2002) Fracture toughness of dental ceramics: comparison of bending and indentation method. Dent Mater18(1): 1219.

4. Mc Laren EA, Whiteman YY (2010) Ceramics: rationale for material selection. Compend Contin Educ Dent 31(9): 666-668.

5. Gibbs CH, Anusavice KJ, Young HM, Jones JS, Esquivel Upshaw JF (2002) Maximum Clenching force of patients with moderate loss of posterior tooth support: a pilot study. J Prosthet Dent 88(5): 498-502.

6. Oh SC, Dong JK, Luthy H, Scharer P (2000) Strength and microstructure of IPS Empress 2 glass-ceramic after different treatments. Int J Prosthodont 13(6): 468-472.

7. Derand T (1974) Effect of variation of the shape of the core on stresses in a loaded model of a porcelain crown. Odontol Revy 25(1): 11-26.

8. Chen HY, Hickel R, Setcos JC, Kunzelmann KH (1999) Effects of surface finish and fatigue testing on the fracture strength of CAD-CAM and pressed ceramic crowns. J Prosthet Dent 82(4): 468-475. 
9. Kelly JR (1999) Dent 81(6): Clinically relevant approach to failure testing of all-ceramic restorations. J Prosthet 81(6): 652-661.

10. Krishnamoorthy CS (2007) Finite Element Analysis: Theory and Programming. 2nd ed. New Delhi: Tata McGraw-Hill Publishing Company Limited.

11. Rosenstiel S, Land M, Fujimoto J (2010) Contemporary fixed Prosthodontics $4^{\text {th }}$ edn, Mosby, St. Louis, pp. 1152.

12. Oyar P, Ulusoy M, Eskitascioglu G (2006) Finite element analysis of stress distribution of 2 different tooth preparation designs in porcelain fused to metal crowns. Int J Prosthodont 19(1): 85-91.

13. IPS e.max (R) (2004) Ceram scientific documentation. Ivoclar Vivadent AG Schaan, Liechtenstein.

14. (2011) Bruxzir Scientific Validation

15. H Hauptmann, D Suttor, S Frank, H Hoescheler (2005) 3M ESPEE A collection of scientific results, pp. 5-33.

16. Proos KA, Swain MV, Ironside J, Steven GP (2002) Finite element analysis studies of an all-ceramic crown on a first premolar. Int J Prosthodont 15(4): 404-412.

17. Hojjatie B, Anusavice KJ (1990) Three-dimensional finite element analysis of glass-ceramic dental crowns. J Biomech 23(11): 1157-1166.
18. Proos KA, Swain MV, Ironside J, Steven GP (2003) Influence of core thickness on a restored crown of a first premolar using finite element analysis. Int J Prosthodont 16: 474-480.

19. Sandu L, Topala F, Porojan S (2012) Effect of preparation depth on stress distribution in premolars restored with MOD pressed ceramics inlays. Recent Researches in Medicine and Medical Chemistry 111(1): 183-186.

20. Reich S, Petschelt A, Lohbauer U (2008) The effect of finish line preparation and layer thickness on the failure load and fractrography of ZrO2 copings. J Prosthet Dent 99(5): 369-376.

21. Oyar P, Ulusoy M, Eskitascioglu G (2014) Finite element analysis of stress distribution in ceramic crowns fabricated with different tooth preparation designs. J Prosthet Dent 112(4): 871-877.

22. Misch C (2005) Dental Implant Prosthetics. (1 $1^{\text {st }}$ edn), St. Louis, Mosby, USA. p. 91.

23. D Souza KM, Aras MA (2017) Three-dimensional finite element analysis of the stress distribution pattern in a mandibular first molar tooth restored with five different restorative materials. J Indian Prosthodont Soc 17(1): 53-60

24. Soares PV, Santos Filho PC, Gomide HA, Araujo CA, Martins LR et al. (2008) Influence of restorative technique on the biomechanical behavior of endodontically treated maxillary premolars. Part II: Strain measurement and stress distribution. J Prosthet Dent 99(2): 114-22. 